\title{
Heavy Lift Launch Capability with a New Hydrocarbon Engine
}

\author{
Grady E. Threet, Jr. ${ }^{1}$, James B. Holt ${ }^{2}$ and Alan D. Philips ${ }^{3}$ \\ NASA, George C. Marshall Space Flight Center, AL, 35812, United States \\ and \\ Jessica A. Garcia ${ }^{4}$ \\ Jacobs, ESTS Group, Huntsville, AL, 35806, United States
}

\begin{abstract}
The Advanced Concepts Office at NASA's George C. Marshall Space Flight Center was tasked to define the thrust requirement of a new liquid oxygen rich staged combustion cycle hydrocarbon engine that could be utilized in a launch vehicle to meet NASA's future heavy lift needs. Launch vehicle concepts were sized using this engine for different heavy lift payload classes. Engine out capabilities for one of the heavy lift configurations were also analyzed for increased reliability that may be desired for high value payloads or crewed missions. The applicability for this engine in vehicle concepts to meet military and commercial class payloads comparable to current ELV capability was also evaluated.
\end{abstract}

\section{Introduction}

$\mathrm{T}$ HE Advanced Concepts Office (ACO) at NASA Marshall Space Flight Center (MSFC) has analyzed over 2000 heavy lift concepts in the last 3 years. These concepts were analyzed for lunar exploration missions, heavy lift capability to low earth orbit (LEO) as well as for exploratory missions to other near earth objects in our solar system. The launch vehicle concepts that ACO has studied and developed have generally been optimized to deliver the maximum payload capability to the desired orbit of interest... in other words, performance driven concepts. With the retirement of the Shuttle fleet, our nation will be without a civil heavy lift launch capability, making the development of a new heavy lift vehicle imperative for future exploration and large science missions.

The majority of the heavy lift concepts analyzed by ACO during the last 3 years have been based on liquid oxygen liquid hydrogen (LOX-LH2) core stage and solids booster stage propulsion technologies (Ares V/Shuttle Derived and their variants). These concepts were driven by the decisions made from the results of the Exploration Systems Architecture Study (ESAS), which in turn, led to the Ares V launch vehicle concept that was baselined in the Constellation Program. Now that the Constellation has been canceled and a Heavy Lift Propulsion Technology Team has been formed, other propulsion options such as liquid hydrocarbon fuels are back in the exploration trade space.

Even with the cancelation of Constellation and Ares V, NASA is still planning exploration missions with the eventual destination of Mars and a new heavy lift launch vehicle is still required to serve as the centerpiece of our nation's next exploration architecture's infrastructure. With an extensive launch vehicle database already developed on LOX-LH2 based heavy lift launch vehicles, ACO initiated a study to look at using a new high thrust $(\geq 1.0 \mathrm{M}-\mathrm{lbf}$ vacuum thrust) hydrocarbon engine as the primary main stage propulsion in such a launch vehicle.

NASA is not the only aerospace entity that could benefit from a new hydrocarbon engine development. The Air Force/Department of Defense (DOD) has expressed a desire for a new domestic produced rocket engine to replace the RD-180 that would also be operable and refurbishable for applications in a reusable launch system. Thus, a joint national engine program could be a possibility with civil and defense space. Emerging commercial launch vehicle companies also have a keen interest in the utilization of new high thrust hydrocarbon engine that would allow them

\footnotetext{
${ }^{1}$ Team Lead Aerospace Engineer, Advanced Concepts Office, George C. Marshall Space Flight Center/ED04.

${ }^{2}$ Aerospace Engineer, Advanced Concepts Office, George C. Marshall Space Flight Center/ED04.

${ }^{3}$ Aerospace Engineer, Advanced Concepts Office, George C. Marshall Space Flight Center/ED04.

${ }^{4}$ Trajectory Engineer, Advanced Concepts Office, George C. Marshall Space Flight Center/ED04. 
to reduce the total number of engines in their stages thereby reducing design and integration complexity and increasing vehicle reliability.

The premise of this study is to determine the thrust level requirement for a new LOX rich staged combustion hydrocarbon engine (NHE) to meet future NASA heavy lift requirements and to develop a family of launch vehicle concepts derived from this new engine that could be utilized in future NASA exploration missions and could serve as a candidate engine for possible DOD and commercial applications.

\section{Study Methodology}

\section{A. ACO Launch Vehicle Tools and Processes}

A general description of the analysis tools utilized by the ACO Launch Vehicle Performance and Sizing Team to generate the preliminary launch vehicle concepts described in this report is listed below.

\section{B. ACO Launch Vehicle Design Tools}

INTegrated ROcket Sizing (INTROS) is an analytical tool that was developed at MSFC to facilitate launch vehicle design and sizing. Written in Visual Basic for Applications, INTROS assists the engineer in four basic tasks: vehicle architecture, launch vehicle sizing, technology and system trade studies, and parameter sensitivity studies. Launch vehicle design and sizing are based on stage geometry and mass properties. Mass properties are established from a large master list of launch vehicle systems, subsystems, propellants and fluids. Mass calculations are based on Mass Estimating Relationships (MERs) that are automatically generated from a large database that is built into the program. Program mass calculation accuracy for existing and historical launch vehicles has been verified to be well within $5 \%$.

Launch Vehicle Analysis (LVA) is a standalone application written at MSFC in Visual Basic that provides quick turnaround launch vehicle structural design and analysis. An important note, this program does not use weight estimating or scaling routines, but supplies detailed analysis by using time proven engineering methods based on material properties, load factors, aerodynamic loads, stress, elastic stability, deflection, etc. For the fastest turnaround, the program is designed to work with the absolute minimum of input data. The output data is purposely limited to the least possible quantity to prevent the analyst from having to dig through a large amount of data for the necessary information. LVA and its predecessors have been serving NASA for over 25 years. Maximum dynamic pressure and acceleration are run as the maximum for the class of vehicle. Loads are run as a single combined worst case.

Program to Optimize Simulated Trajectories (POST3D) is a FORTRAN 77 based legacy code developed by NASA Langley for detailed trajectory simulations. POST is a generalized point mass, discrete parameter targeting and optimization program. POST provides the capability to target and optimize point mass trajectories for a powered or unpowered vehicle near an arbitrary rotating, oblate planet. POST has been used successfully to solve a wide variety of atmospheric ascent and reentry problems, as well as exoatmospheric orbital transfer problems. The generality of the program is evidenced by its N-phase simulation capability which features generalized planet and vehicle models. This flexible simulation capability is augmented by an efficient discrete parameter optimization capability that includes equality and inequality constraints.

\section{The ACO Launch Vehicle Performance and Sizing Process}

The process used for the preliminary performance and sizing of the launch vehicles in this paper is shown in Figure 1. Based upon the mission requirements for the particular concept under study and within the framework of the groundrules and assumptions established, a preliminary concept is sized using the MERs in INTROS. An initial trajectory of this vehicle is analyzed in POST to determine the ascent flight environments (accelerations, dynamic pressure, payload capability, etc.) and then the initial vehicle weights and trajectory outputs are sent for more detailed structural sizing with LVA. Loads, forces, material properties, design techniques are all considered within the LVA analysis and new structural weights are calculated for the launch vehicle concept. INTROS then incorporates these new structural element weights and estimates a total injected mass based on the total ideal delta velocity (delta V) from the previous POST output. POST then determines a new total injected mass and delta V. INTROS takes these values from POST and estimates a new value for propellant reserves and continues to iterate with POST until the POST total injected mass is within $0 \mathrm{lb}$ to $300 \mathrm{lb}$ of the INTROS estimated value. The performance and sizing analysis for this concept is then considered closed and a vehicle summary is generated. 
If a cost analysis of the concept is to be performed, the vehicle configuration description and mass summary for the vehicle and it's elements are then sent to the cost team. Likewise, if a reliability analysis is to be performed, the vehicle configuration description and closed case trajectory summary are sent to the reliability team. For the vehicles described in this paper, cost and reliability analyses were not requested.

\section{Advanced Concepts Launch Vehicle Analysis Process}

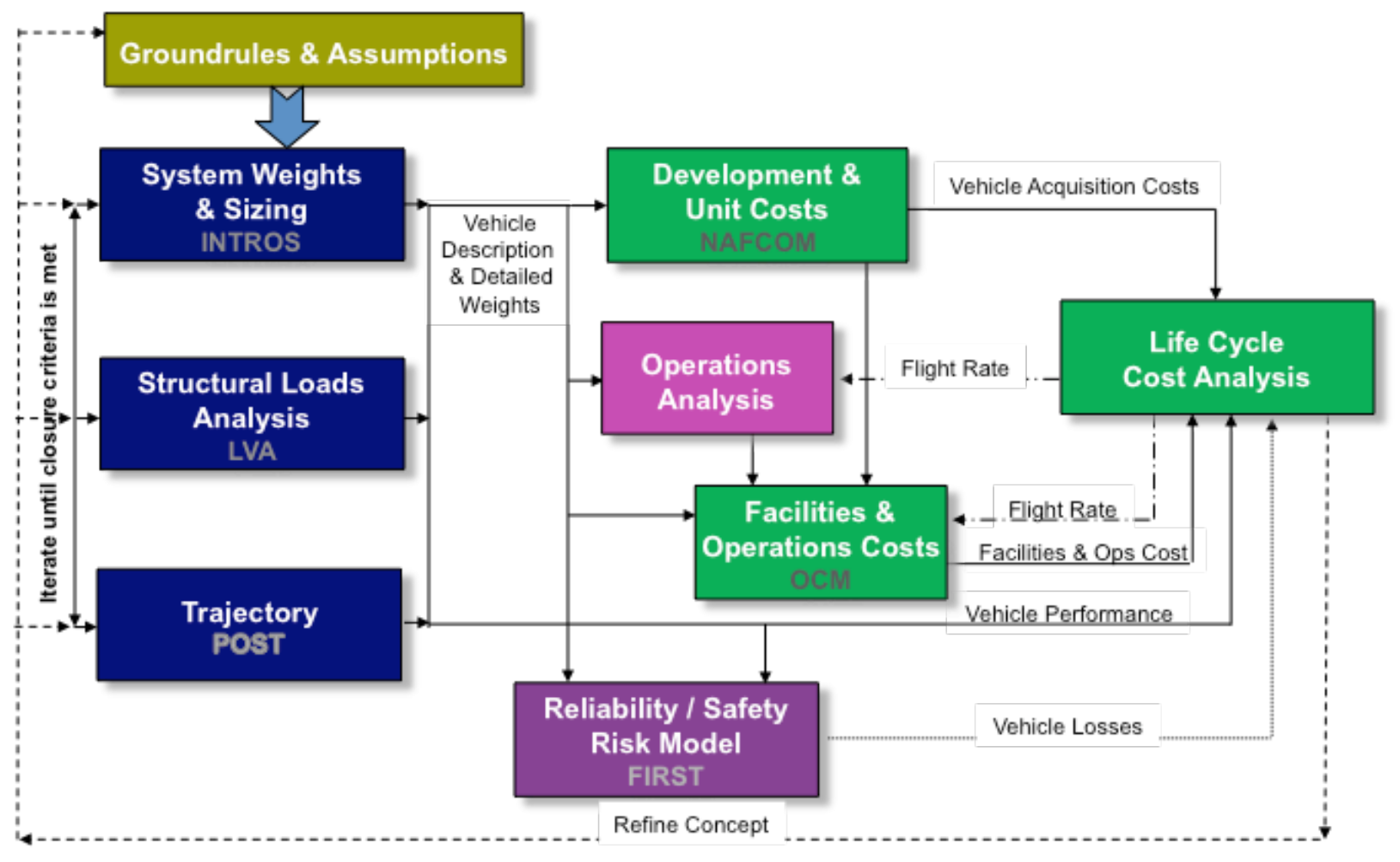

Processes can be adjusted if necessary

Figure 1 Launch Vehicle Process

\section{Study Approach}

The approach that the ACO Launch Vehicle Sizing Team took to analyzing this subject fits within the constraints set in the Ground Rules and Assumptions listed in the Appendix of this paper and using the processes described in the Tools and Processes section of this paper.

The approach was to determine the thrust level of the NHE that is required to deliver 100 metric tons (mt) of payload to LEO in a two stage series burn configuration with the second stage being a LOX-LH2 propellant combination. After the engine thrust was determined for this vehicle, the team then evaluated if two liquid rocket boosters (LRB) with the same engine in each LRB added to the $100 \mathrm{mt}$ vehicle could increase the payload capacity to $140 \mathrm{mt}$. The $100 \mathrm{mt}$ and $140 \mathrm{mt}$ payload targets were chosen for design points in this study because those payload masses in LEO can capture many of NASA's significant exploration missions in a one or two launch scenario.

If $100 \mathrm{mt}$ and $140 \mathrm{mt}$ launch vehicles can be achieved using this approach, then the next goal of the study was to see if totally common stages (both first and second stages, except for the liquid strap-on booster attach structure) could be utilized for both vehicles $(100 \mathrm{mt}$ and $140 \mathrm{mt})$ to reduce design, development, and testing costs and manufacturing complexity. The worst case loads from the trajectory analyses of both vehicles would drive the structural design of both stages. This total commonality approach would not produce totally optimized launch 
vehicle concepts, but if the payload penalty was not too severe, significant cost savings could be realized for the design, production, and operation of the vehicles.

For the purpose of this study, J-2X-285 engines were selected for use in the second stages of these vehicle configurations.

\section{Study Analyses}

\section{A. Determining the NHE Thrust for the Concept Family}

Several concept iterations were run for a two stage series burn vehicle to attempt to achieve $100 \mathrm{mt}$ to LEO. The performance parameters assumed for the NHE and the J-2X-285 were given the study team by the ER21 engine group at MSFC and are shown in Table 1.

Table 1 Engine Characteristics Assumed in the Study

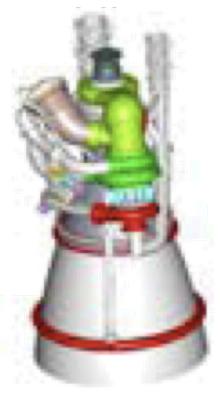

\section{NHE Engine Assumptions}

- Vac Isp: $332 \mathrm{~s}$

- $\mathrm{T} / \mathrm{W}=70$

- Mixture Ratio: 2.7

- Engine Length: 180 in.

- Engine Nozzle Diam: 120 in.

\section{J-2X -285 Assumptions}

- Vac Thrust: 285,000 lbf

- Vac Isp: $436 \mathrm{~s}$

- $\mathrm{T} / \mathrm{W}=53$

- Mixture Ratio: 5.5

- Engine Length: 131 in.

- Engine Nozzle Diam: 80.5 in.

Based upon the estimated engine dimension information we received from the ER21, the maximum number of engines that could be comfortably arranged inside of a $33 \mathrm{ft}$. diameter stage was six when accounting for a six degree gimbal pattern for each engine. The ER21 engine group also recommended that the maximum vacuum thrust level to be considered in this study to be no more than $1.3 \mathrm{M}$-lbf vac because of limits of the manufacturing facility for a single chamber/nozzle for a staged combustion cycle. Preliminary trades for the second stage showed that four of the J-2X-285 engines was preferable for best performance results with a six NHE first stage. The initial thrust level was set at $1.0 \mathrm{M}$-lbf for the NHE but the resulting performance of the vehicle was below $100 \mathrm{mt}$. The thrust level was increased until it reached $1.17 \mathrm{M}-\mathrm{lbf}$ vac, when at that level, $100 \mathrm{mt}$ of performance was achieved. The propellant loads of both the first and second stages were optimized each time to maximize the injected mass. Once the initial $100 \mathrm{mt}$ concept was sized, a pair of LRBs were sized and attached to the $100 \mathrm{mt}$ vehicle design, each using the same $1.17 \mathrm{M}-\mathrm{lbf}$ vac engine, to determine if the payload capability could be increased to $140 \mathrm{mt}$ to LEO. The first and second stage propellant loads were also re-optimized since the delta $\mathrm{V}$ splits on the vehicle changed with the addition of the LRBs. This concept was considered marginal because it came in just under $140 \mathrm{mt}$, so it was decided to increase the engine thrust again to achieve $140 \mathrm{mt}$ with some margin. A $1.25 \mathrm{M}$-lbf thrust level was next analyzed for this configuration. Again the propellant loads were optimized for the first and second stages as well as the LRBs and the resulting vehicle concept produced a payload capability of $143.7 \mathrm{mt}$.

\section{B. Commonality Analysis for the Concept Family}

Since vehicle stage commonality was also a desired objective of this study to reduce design, production, and operation costs for a family of vehicles, an analysis was performed to determine whether the $100 \mathrm{mt}$ vehicle concept could be achieved from the first and second stages of the $140 \mathrm{mt}$ vehicle without modification to the stages. To meet the 1.2 minimum thrust/weight ground rule at liftoff, propellant had to be offloaded from the vehicle since the additional thrust from the LRBs was no longer available. The amount of propellant offload was determined for both stages that produced the maximum payload capability for the vehicle. This resulted in a vehicle capability of 104.2 mt using stages common with the $140 \mathrm{mt}$ vehicle.

Vehicle analysis to determine the feasibility of the LRB from the $140 \mathrm{mt}$ vehicle used as the first stage in a two stage series burn vehicle was also performed to determine the capability it could achieve for lower payload launch requirements. This approach, emphasizing commonality, produces a family of vehicle concepts for three payload classes from the same launch vehicle stage elements and engines. Since the $100 \mathrm{mt}$ vehicle contains a rather high number of engines, further analyses were performed to determine the payload capability of this vehicle with engine 
out scenarios. These vehicles with their corresponding ACO reference number are shown below in Figure 2. A more detailed discussion of these vehicle configurations is given in the following sections of this paper.

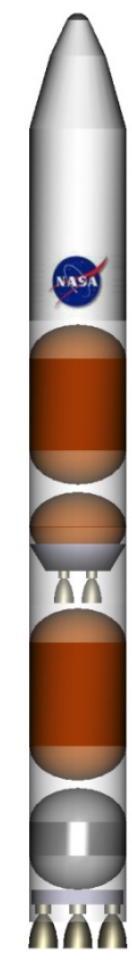

114.05 .00

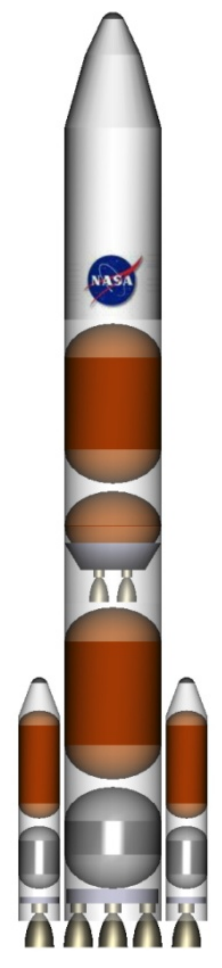

114.04 .00

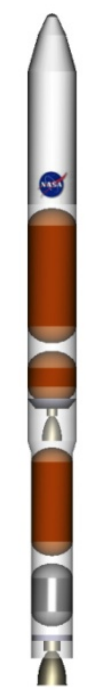

114.01 .02

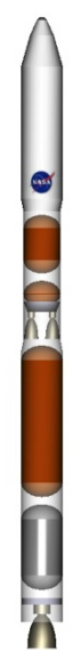

114.09.00

Figure 2 The Family of Vehicles

\section{C. $140 \mathrm{mt}$ Configuration (114.04.00)}

This concept is a two and a half stage vehicle with strap-on LRBs. Six LOX-RP rocket engines provide the thrust for the first stage. The engines are arranged in a circular pattern around the $33.0 \mathrm{ft}$ diameter stage. Engine fairings are included to accommodate the first stage engine nozzles gimballing outside the stage diameter. Each engine provides 1.08 M-lbf of sea level thrust (1.25 M-lbf@vac) for a combined liftoff thrust of 6.5 M-lbf. This new staged combustion engine also was assumed to have a vacuum Isp of 332.0 secs. The propellant load of the first stage provides $4.07 \mathrm{M}-\mathrm{lbm}$ of usable ascent propellant for the first stage engine cluster. The first stage tanks were sized with the NHE Mixture Ratio (MR) of 2.70. An intertank separates the propellant tanks with the LOX tank located forward of the Rocket Propellant (RP) tank.

The second stage consists of four J-2X-285 LOX-LH2 engines. This engine is a shorter nozzle version of the J$2 \mathrm{X}$ and can be clustered in upper stages much like the J-2 in the S-II stage of the Saturn V rocket. The second stage diameter matches the first stage diameter of $33.0 \mathrm{ft}$ providing ample room for engine gimbal checkout while stacked on the launch pad prior to launch. The truncated nozzle reduces the engine vacuum Isp to 436.0 secs. The four engine cluster produces a total stage vacuum thrust of $1.14 \mathrm{M}$-lbf. The propellant load in the second stage tanks provides $1.08 \mathrm{M}-\mathrm{lbm}$ of usable propellant. The tanks are separated by an intertank with the LOX tank aft of the LH2 tank. The J-2X-285 engine MR of 5.50 sets the oxidizer to fuel split of the stage and, consequently, the size of each of these tanks.

The strap-on LRBs utilize the same 1.08 M-lbf@SL/1.25M-lbf@Vac LOX-RP engine as the first stage in an effort to maximize commonality between elements and to reduce the development cost of the vehicle. This new common engine requires a minimum LRB diameter to safely gimbal the engine nozzle and not protrude into the free stream flow during ascent. An intertank separates the propellant tanks with the LOX tank located forward of the RP 
tank. These tanks are sized for the 2.70 engine MR. Each LRB contains $501 \mathrm{k}-\mathrm{lbm}$ of propellant. The vehicle arrangement of the $140 \mathrm{mt}$ configuration (ACO Vehicle \# 114.04.00) is shown in Figure 3.

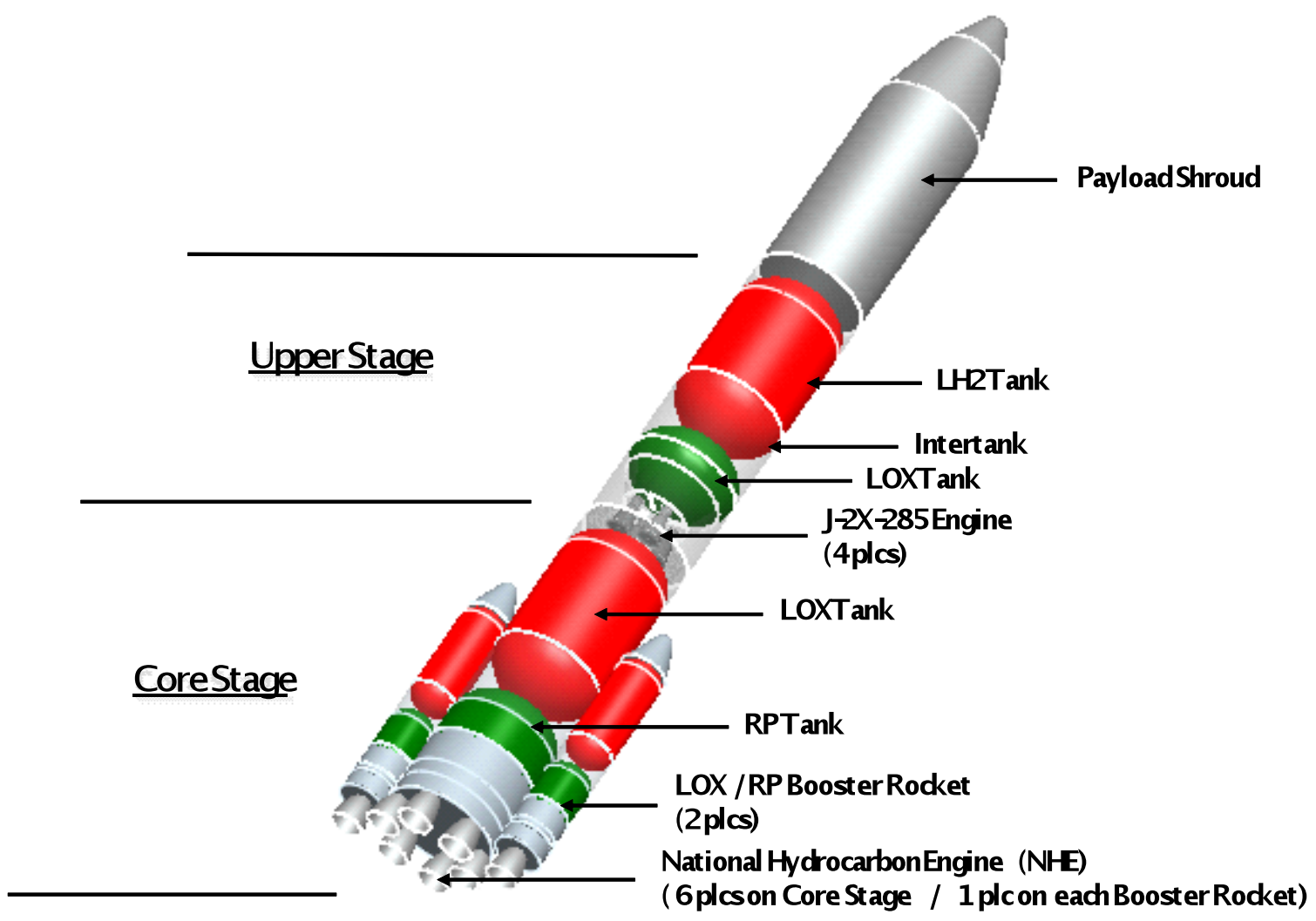

Figure 3 114.04.00 Systems Design

A standard biconic shroud protects the cargo during ascent. The diameter of the shroud matches the second stage diameter of $33.0 \mathrm{ft}$. The cylindrical portion of the shroud is $65.6 \mathrm{ft}$ in length. This length provides a payload density $<7.0 \mathrm{lbm} / \mathrm{ft}^{3}$ in the cylindrical section of the shroud. The overall vehicle dimensions of the $140 \mathrm{mt}$ configuration (ACO Vehicle \# 114.04.00) are shown in Figure 4. 


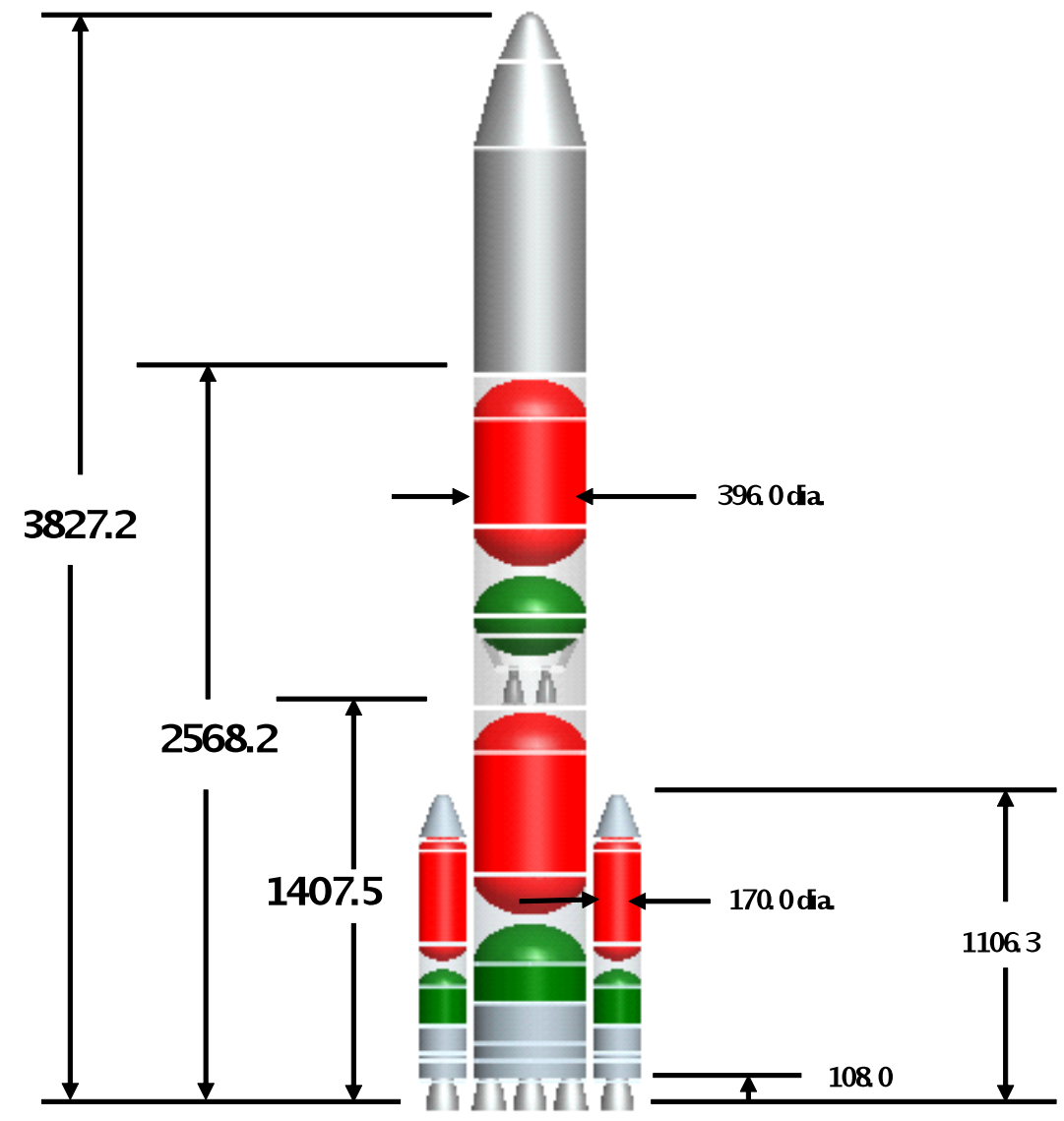

NOTE Alldimensionsare inches

\section{Front View}

Figure 4 114.04.00 Front View

\section{LRB Design Considerations}

The Space Transportation System (STS) utilizes a forward attach to introduce the thrust loads from the Solid Rocket Boosters (SRBs) into the External Tank's (ET's) intertank. This has multiple positive benefits for the Space Shuttle. For control purposes, the ET LOX tank is required to be forward on the vehicle. This arrangement places a large compression load on the long LH2 tank making it very heavy. However, with the thrust loads from the SRBs being introduced into the intertank, those compression loads are partially cancelled out. This saves a great amount of weight in the $\mathrm{LH}_{2}$ tank. Since the SRBs contain a high pressure (approaching $1000 \mathrm{psi}$ ), the forward thrust point attachment does not have much affect on the SRB weight. The high pressure within the SRBs cancels a great deal of the loads from the ET. A win/win situation that is rare in aerospace applications.

In the set of configurations that are being presented here, the opposite approach for booster attachment is being taken. The thrust loads from the boosters are being introduced at the aft end of the core vehicle. The benefits for this approach are many for this type of configuration. First, the pressure in the propellant tanks of the LRB is very low ( $\sim 50 \mathrm{psia})$ compared to the pressure inside the case of an SRB. If the same type of forward attach was used for the LRB that is used for the SRBs in the STS, there would be a significant weight growth to the LRB structural elements. Second, the placement of the intertank on the core vehicle is unconstrained making optimizing the vehicle much easier. Third, this results in only a slight difference on the flight loads between vehicle 114.04 .00 and vehicle 114.05.00.

The ideal delta $\mathrm{V}$ split between the elements is derived from previous work with a similar concept to provide a payload of $140 \mathrm{mt}$ to LEO. In this case the LEO injection orbit is defined as a $30 \mathrm{nmi} \times 130 \mathrm{nmi}$ elliptical orbit at 29.0 degrees inclination. For this configuration, the boost phase of flight provides $28.4 \%$ of the total ideal delta $\mathrm{V}$. 
The first stage continues to burn after LRB jettison and provides an additional $15.3 \%$ of the total ideal delta V. The second stage burn contributes the remaining 56.3\% of the ideal delta $\mathrm{V}$ during the final burn to orbit. This configuration delivers $143.7 \mathrm{mt}$ of payload to LEO.

This vehicle lifts off with a thrust to weight of 1.20. During the liquid booster burn it reaches a maximum dynamic pressure of 671 pounds force per square foot (psf) at 85.5 seconds into the flight. The liquid boosters burn out at 133.07 seconds into the flight and at an altitude of 121,915 ft with a speed of mach 4.45. At separation the dynamic pressure is $127.6 \mathrm{psf}$. The maximum acceleration for the liquid booster portion of the ascent is $3.10 \mathrm{~g}$ 's and occurs at burn out. The first stage continues to burn until 180.38 seconds into the flight at which point it reaches a maximum acceleration of $3.84 \mathrm{~g}$ 's and a mach of 8.86 . The core burnout occurs at an altitude of $230,959 \mathrm{ft}$. Four seconds after the first stage separates the upper stage ignites with an initial thrust to weight of $0.727 \mathrm{~g}$ 's at an altitude of 242,496 ft. At ignition the upper stage has a speed of mach 8.96. The shroud is jettisoned 239.5 seconds into the flight at a mach of 8.02 and an altitude of $376,034 \mathrm{ft}$. At 598.74 seconds into the flight the upper stage burns out and inserts into an orbit of 30 by 130 nautical miles at an altitude of 87.6 nautical miles. At burnout the upper stage has a thrust to weight of $2.52 \mathrm{~g}$ 's and is flying at a mach of 11.99 .

\section{E. 100 mt Configuration (114.05.00)}

The $100 \mathrm{mt}$ to LEO concept begins with the $140 \mathrm{mt}$ vehicle and removes the two LRBs. The first and second stages of the $140 \mathrm{mt}$ vehicle are now the propulsive stages of the $100 \mathrm{mt}$ vehicle. Once the LRBs are removed the thrust to weight of the stack at liftoff decreases below the minimum ground rule value of 1.20. This requires a propellant offload from one or both stages. Several iterations were analyzed varying the offload of propellant in the first and second stages of the vehicle to determine the maximum payload capability while meeting the $1.2 \mathrm{~T} / \mathrm{W}$ liftoff groundrule. The first stage propellant (LOX-RP) was offloaded $387.0 \mathrm{k}-\mathrm{lbm}$ leaving $3.69 \mathrm{M}-1 \mathrm{bm}$ for the six NHE cluster. Offloading $130.8 \mathrm{k}-\mathrm{lbm}$ of LOX-LH2 leaves $954.6 \mathrm{k}-\mathrm{lbm}$ of usable propellant in the second stage.

Removal of the LRBs reduces the LEO payload by $39.5 \mathrm{mt}$ down to $104.2 \mathrm{mt}$. The ideal delta V split for this configuration increases the second stage contribution to $59.7 \%$. The remaining $40.3 \%$ is provided by the first stage propulsion system. The vehicle configuration arrangement of the $100 \mathrm{mt}$ configuration (ACO Vehicle \# 114.05.00) is shown in Figure 5 and the overall vehicle dimensions are shown in Figure 6. 


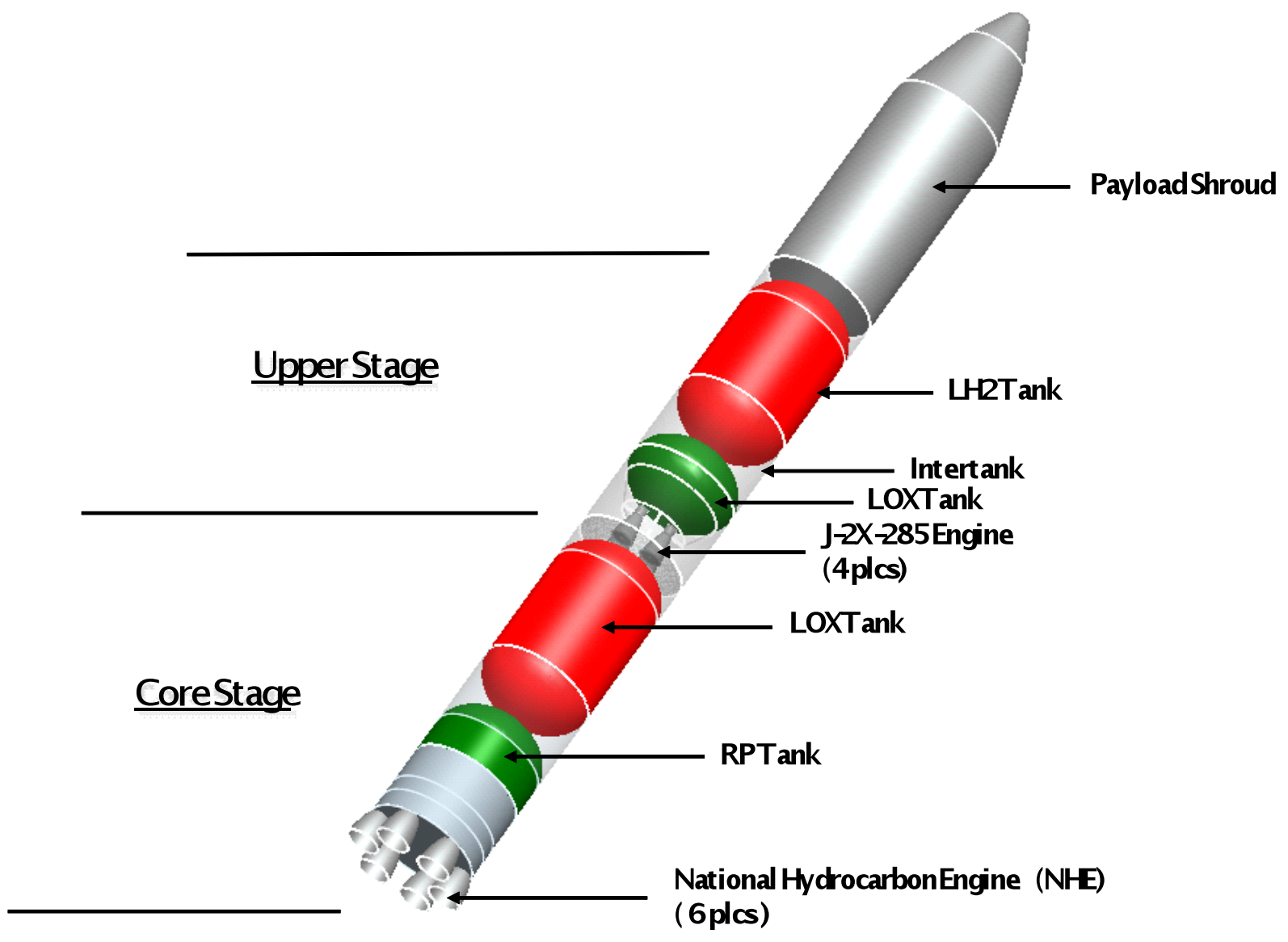

Figure 5 114.05.00 Systems Design 


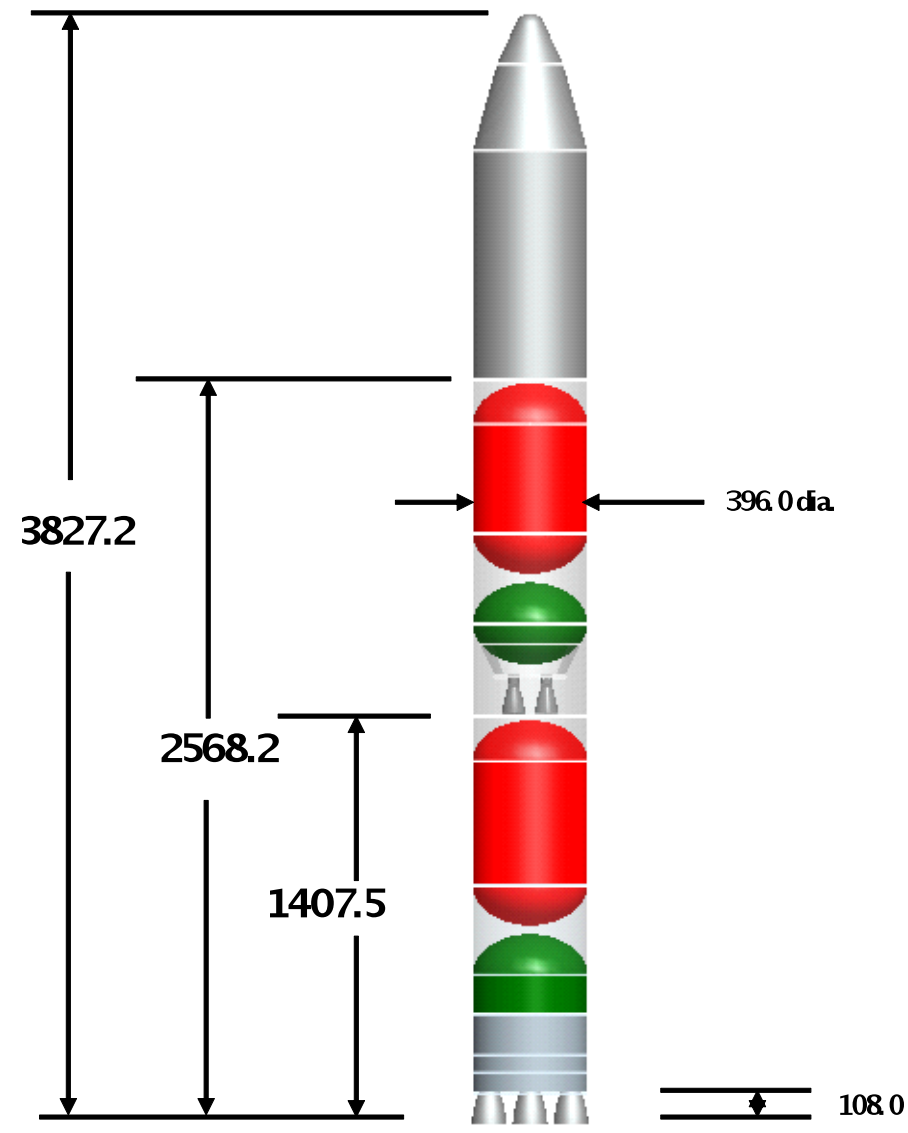

NOTE Alldimensionsare inches

\section{Front View}

Figure 6 114.05.00 Front View

Vehicle 114.05.00 lifts off with a thrust to weight of 1.20. During the first stage burn it reaches a maximum dynamic pressure of $673 \mathrm{psf}$ at 85.5 seconds into the flight. To avoid exceeding the same maximum acceleration as the vehicle with boosters the first stage begins a continuous throttle at 153.81 seconds and an altitude of $165,777 \mathrm{ft}$. The first stage continues to burn until 163.82 seconds into the flight where it reaches a maximum acceleration of $3.85 \mathrm{~g}$ 's and a mach of 7.34. Burnout occurs at an altitude of 190,596 ft. Four seconds after the first stage separates the upper stage ignites with an initial thrust to weight of $0.841 \mathrm{~g}$ 's at an altitude of $200,911 \mathrm{ft}$ and a speed of mach 7.40. At 261.22 seconds into flight the shroud is jettisoned at a mach of 8.15 and at an altitude of $376,034 \mathrm{ft}$. At 532.89 seconds into flight the upper stage inserts into an orbit of 30 by 130 nautical miles at an altitude of 87.3 nautical miles. At burnout the upper stage has a thrust to weight of $3.15 \mathrm{~g}$ 's and is traveling at mach 12.05 .

\section{F. Conversion of LRB to Inline First Stage (114.01.02)}

This concept is a two stage series burn vehicle derived from the LRBs used in the 114.04.00 vehicle. The first stage consists of the LRB with the nosecone removed. The LOX-LH2 second stage hammerheads out to a diameter of 200 inches. A single J-2X-285 is used to maintain engine commonality with the parent vehicle, 114.04.00. An intertank separates the propellant tanks with the LOX tank aft of the LH2 tank. These tanks provide $255.9 \mathrm{k}-\mathrm{lbm}$ of usable propellant. Stage burn time is $391.4 \mathrm{sec}$.

The shroud nosecone is a biconic shape with a cylindrical length of $45.2 \mathrm{ft}$. The diameter of the shroud matches the second stage diameter of 200 inches. This shroud volume results in a payload density $<5.0 \mathrm{lbm} / \mathrm{ft}^{3}$ for this concept which delivers $12.9 \mathrm{mt}$ of payload to LEO. This is similar to the LEO capability of the Atlas V 400 series. The single engine first stage provides only $27.7 \%$ of the total ideal delta V leaving the bulk, $72.3 \%$, of the work to 
the second stage. The vehicle configuration arrangement of vehicle 114.01.02 is shown in Figure 7 and the overall vehicle dimensions are shown in Figure 8.

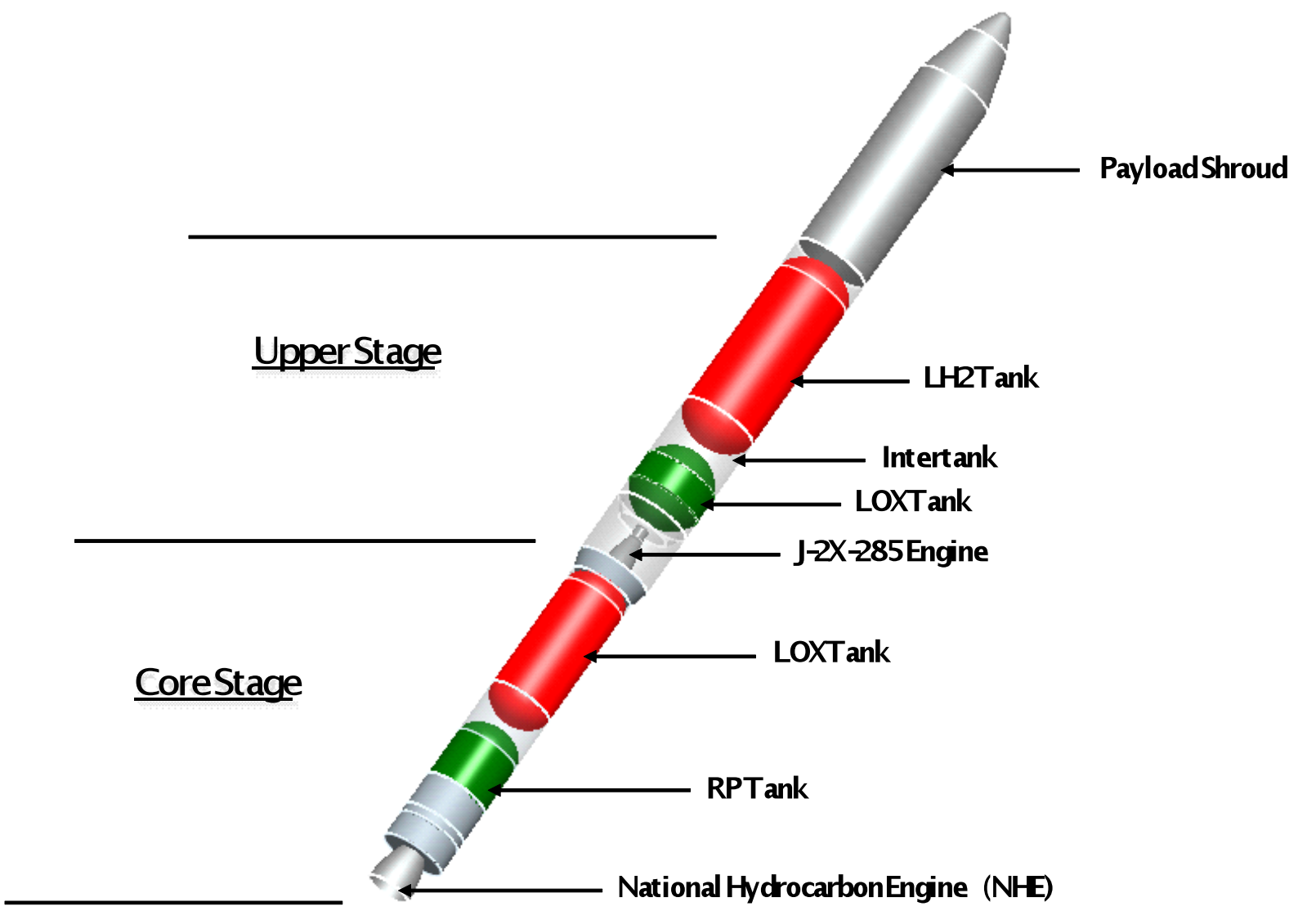

Figure 7 114.01.02 System Design 


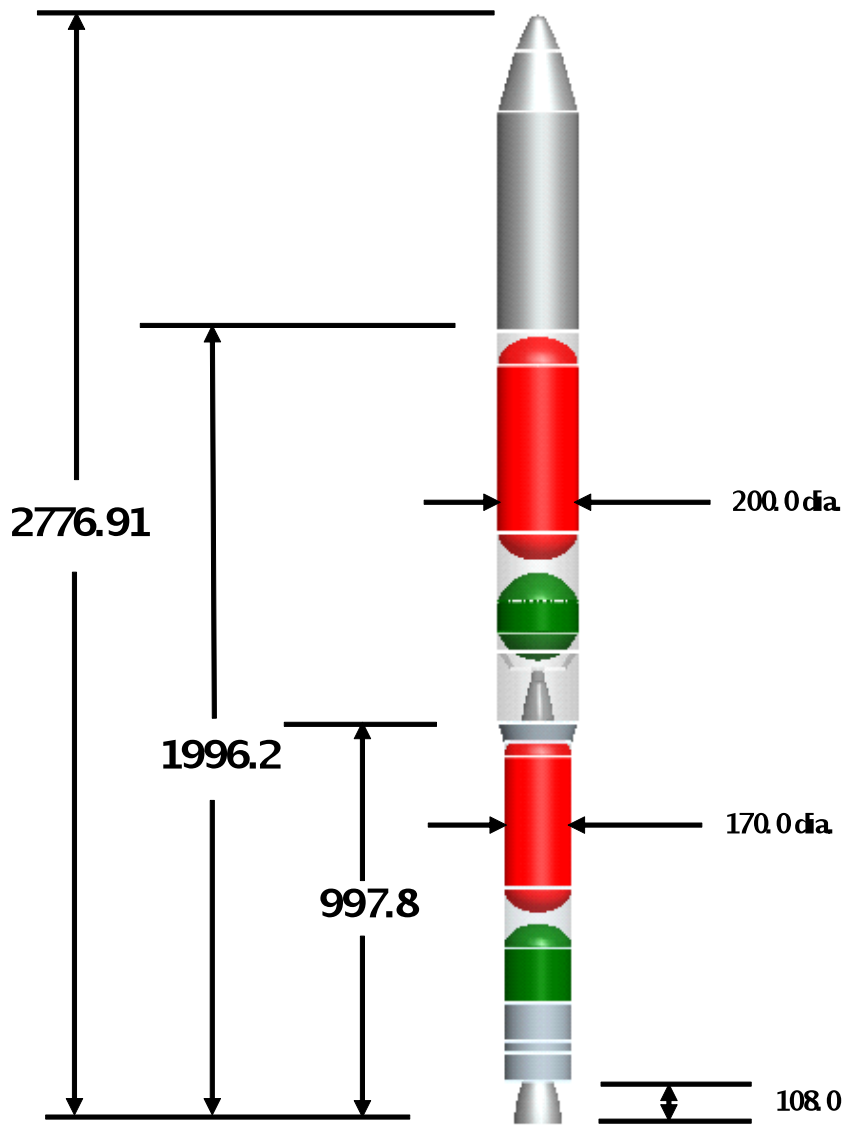

NOTE Alldimensionsare inches

Front View

Figure 8 114.01.02 Front View

\section{G. Loads Analysis Comparison for the LRB in Vehicles 114.04.00 and 114.01.02}

Loads analyses comparing the pre-launch loads and flight loads environments between the LRB as a strap-on (114.04.00) and the LRB as a first stage in an inline configuration (114.01.02) are substantially different. The booster as a first stage configuration has a much higher bending moment since the overall vehicle length is much longer with the second stage attached. The bending moment for this vehicle is nearly nine times higher then bending moment for the booster used as a strap-on. But the LRB, as a strap-on has a much higher compression load on the aft end where it transmits the thrust loads into the core. The compression load on the strap-on booster is one and a half times higher than the compression load on vehicle 114.01.02. To incorporate both of these load environments into the LRB design will make the booster slightly heavier than it would be for each specific application by itself. However, for the sake of commonality, the structural weight increases were assumed in the LRB applications for both vehicles. The overall affect of this structural weight increase on the payload capabilities for both vehicles (114.04.00 and 114.01.02) is small however, since the LRBs are jettisoned relatively early in flight in both scenarios. The loads analysis results discussed above are show below in Figures 9 and 10. 


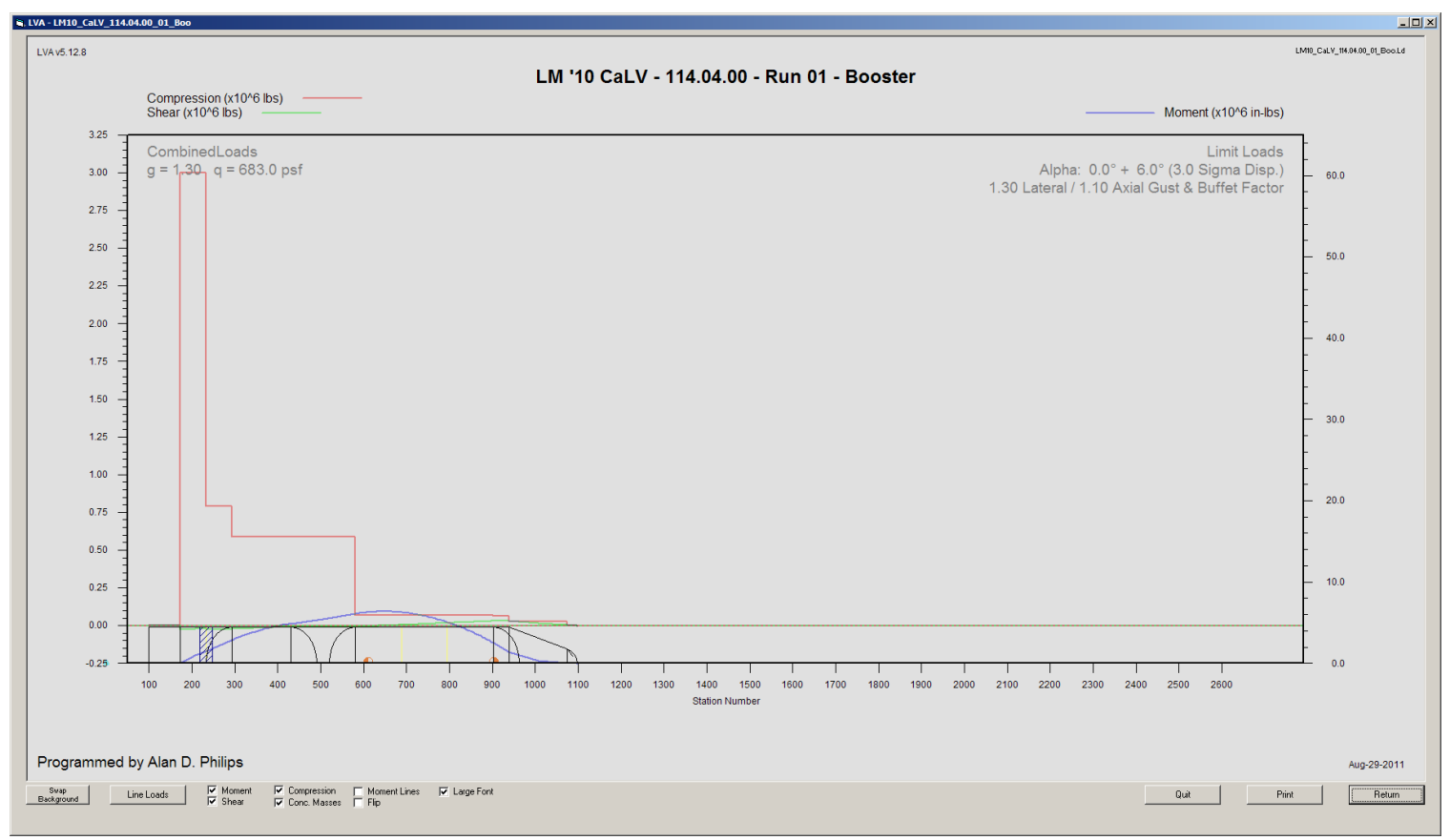

Figure 9 Combined Loads for the LRB as a Strap-on Booster 114.04.00

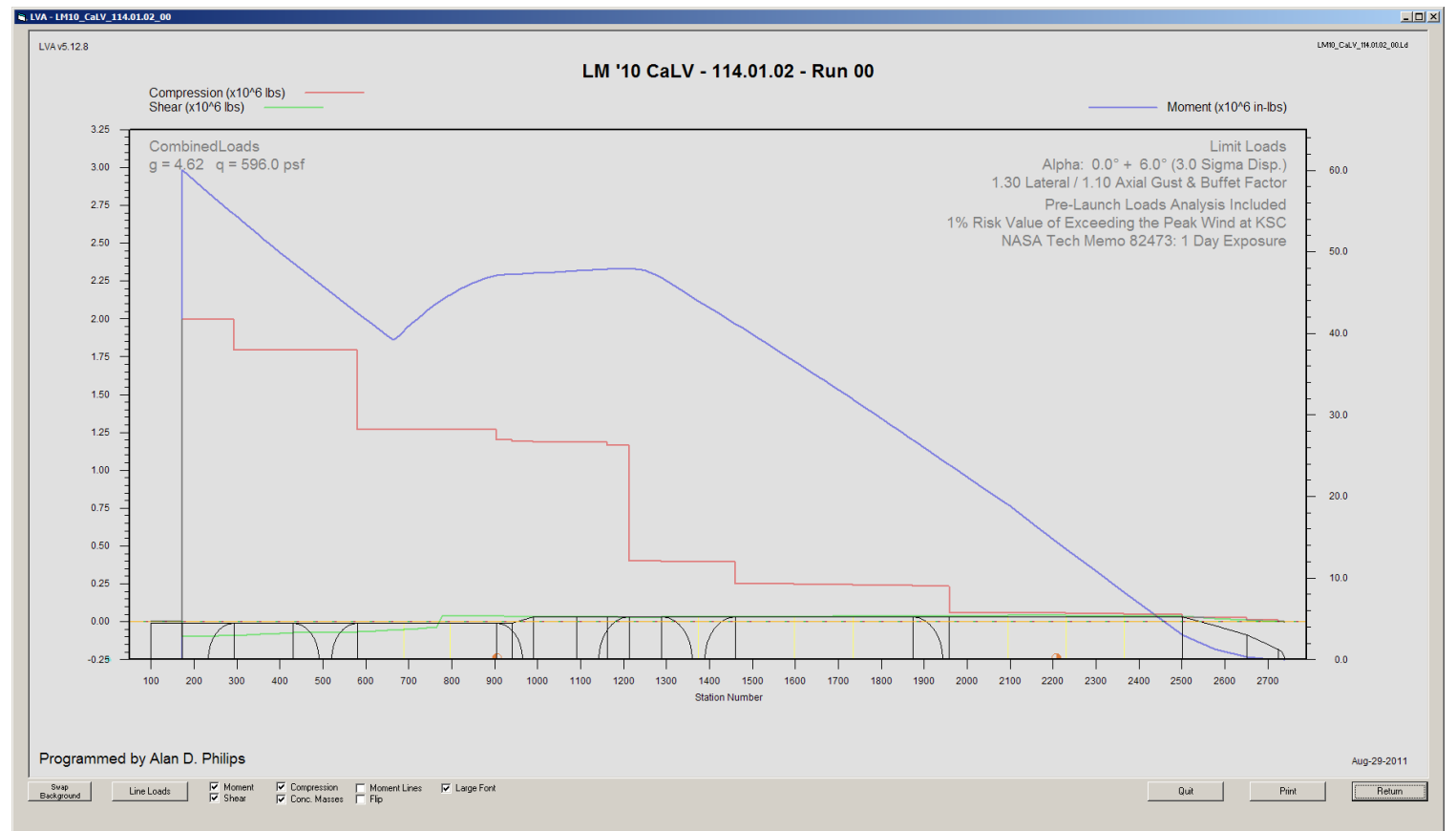

Figure 10 Combined Loads for the LRB as a First Stage Configuration 114.01.02 
Vehicle 114.01.02 lifts off with a thrust to weight of 1.20. During the first stage burn it reaches a maximum dynamic pressure of $586 \mathrm{psf}$ at 82.0 seconds into the flight. The first stage continues to burn until 133.07 seconds into the flight where it reaches a maximum acceleration of $3.11 \mathrm{~g}$ 's and a speed of mach 4.01. First stage burnout occurs at an altitude of $138,295 \mathrm{ft}$. Four seconds after the first stage separates the upper stage ignites at an altitude of 148,544 ft with an initial thrust to weight of $0.863 \mathrm{~g}$ 's and a speed of mach 3.90. At 237.50 seconds into flight the shroud is jettisoned at a speed of mach 5.95 and an altitude of $346,835 \mathrm{ft}$. At 528.45 seconds into the flight the upper stage inserts into an orbit of 30 by 130 nautical miles at an altitude of 87.4 nautical miles. At burnout the upper stage has a thrust to weight of $4.52 \mathrm{~g}$ 's and is traveling at a speed of mach 12.04 .

\section{H. LRB with Stretched Tanks as Inline First Stage (114.09.00)}

This two stage series burn concept starts with the LRB from 114.04 .00 and stretches the first stage tanks until the thrust to weight at liftoff is 1.20 . This reduces the commonality of the LRB that was emphasized in the previous configuration (114.01.02) but produces a concept very similar to the Atlas V except that the second stage is not assumed to be pressure stabilized as is the Centaur of the Atlas V. The second stage of this concept replaces the single J-2X-285 engine with two RL-10A4-3 engines and the diameter is reduced to 150 inches. The tank arrangement remains the same as before but the MR increases to 5.88 for the RL-10 engines. This smaller second stage contains only $59 \mathrm{k}$ of usable propellant optimized for a LEO mission. This configuration delivers $11.5 \mathrm{mt}$ of payload to LEO. There is a noted difference in the ideal delta V split from the previous case. The stretched first stage contribution increases to $55.6 \%$ of the total ideal delta $\mathrm{V}$. The more efficient second stage provides the remaining $44.4 \%$ of the ideal delta V. When this concept is flown for a geosynchronous transfer orbit (GTO) it delivers $4.2 \mathrm{mt}$ of payload. If a Centaur type structural design was assumed and mass growth contingency removed, approximately $3 \mathrm{mt}$ of increased payload capability could be obtained. The vehicle configuration arrangement of vehicle 114.09.00 is shown in Figure 11 and the overall vehicle dimensions are shown in Figure 12.

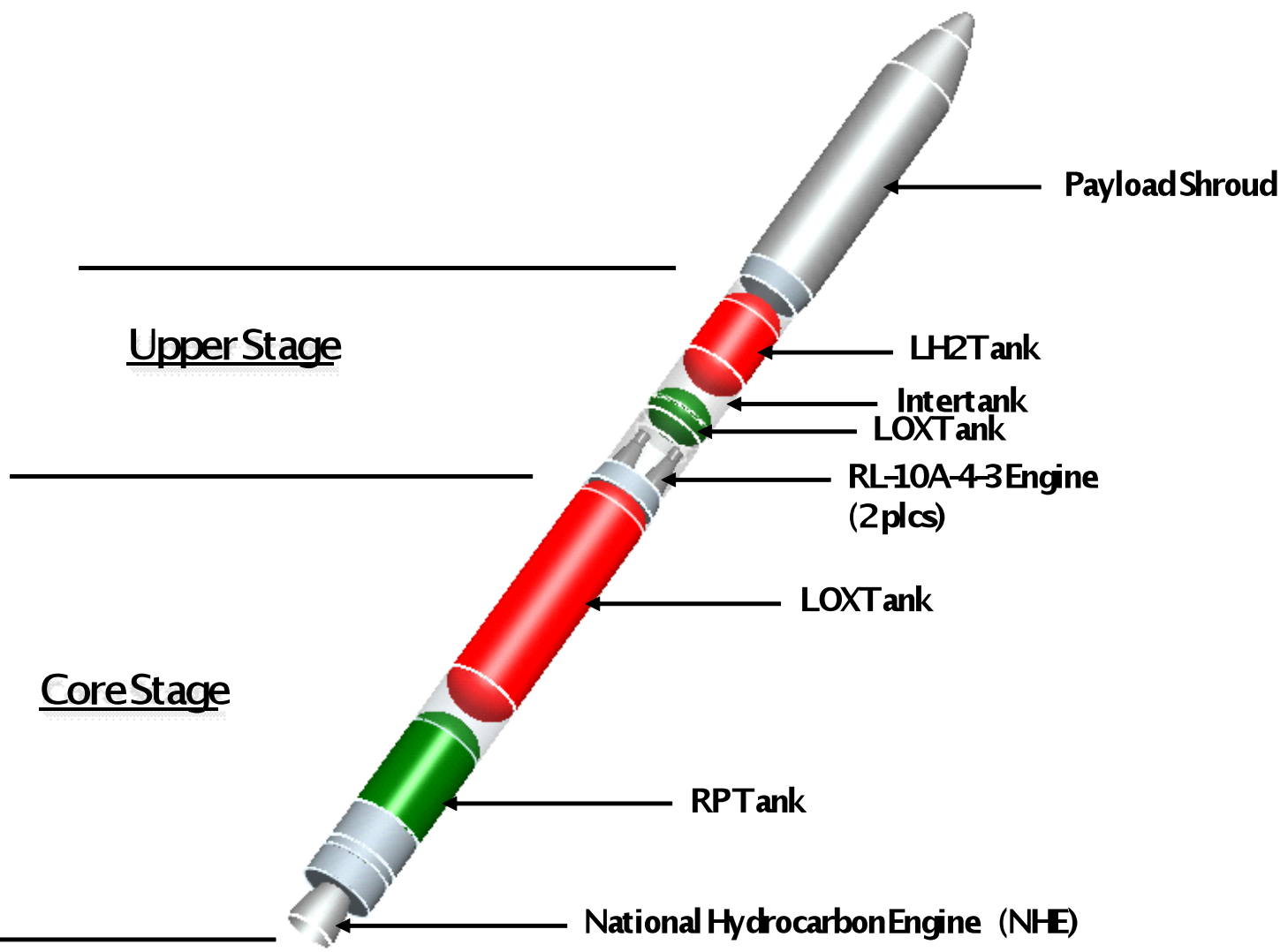

Figure 11 114.09.00 Systems Design 


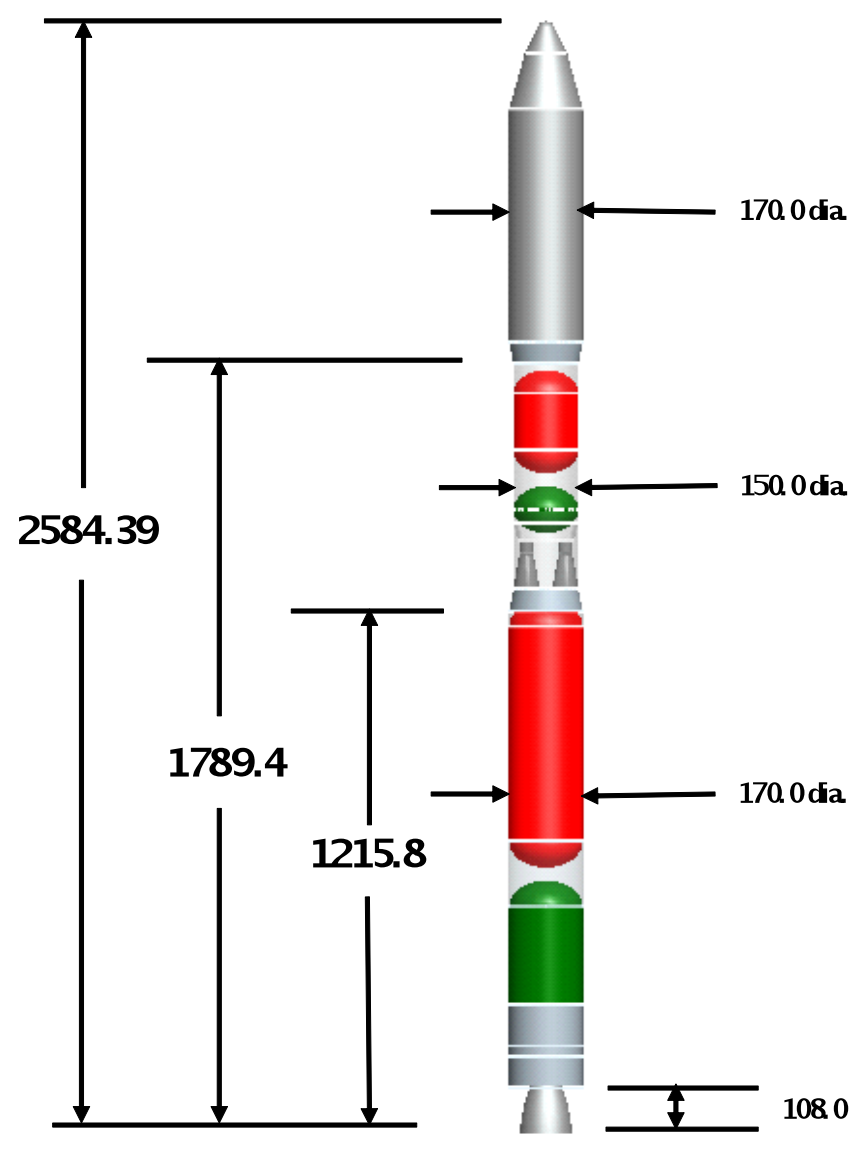

NOTE Alldimensionsare inches

\section{Front View}

Figure 12 114.09.00 Front View

Configuration 114.09.00 uses the same dry structure in the first stage as configuration 114.01 .02 except that the propellant tanks are stretched to accommodate more propellant. The pre-launch and flight loads for this vehicle were generated for this configuration alone, i.e. it does not carry additional weight for commonality with the other configurations.

This vehicle lifts off with a thrust to weight of 1.20. During the first stage burn it reaches a maximum dynamic pressure of $669 \mathrm{psf}$ at 85.5 seconds into the flight. The first stage begins to throttle at 172 seconds into the flight in order to maintain a maximum acceleration of $5 \mathrm{~g}$ 's. At this point it has reached an altitude of 209,898 ft and speed of mach 8.76. The first stage continues to burn until 193.75 seconds into the flight where it reaches a speed of mach of 13.11. First stage burnout occurs at an altitude of $279,815 \mathrm{ft}$. Four seconds after the first stage separates the upper stage ignites with an initial thrust to weight of $0.863 \mathrm{~g}$ 's. At ignition the upper stage is at an altitude of $294,232 \mathrm{ft}$ and traveling at mach 13.20. At 229.00 seconds into flight the shroud is jettisoned at a speed of mach 9.31 and an altitude of 396,994 ft. At 759.25 seconds into flight the upper stage inserts into an orbit of 30 by 130 nautical miles at an altitude of 104.7 nautical miles. At burnout the upper stage is traveling at a speed of mach 10.81 and has a thrust to weight of $1.25 \mathrm{~g}$ 's. 


\section{Engine Out Analyses of the $\mathbf{1 0 0}$ mt Vehicle Concept}

The launch vehicle concepts analyzed in this study are performance driven designs, sized to maximize injected mass into orbit for the configuration within the context of the ground rules and assumptions of the study. These vehicle designs also utilize a large number of engines in their respective stages; six in the first stage and four in the second stage. Because of the relatively high number of engines in these concepts, launch vehicle reliability, even though not analyzed in this study, could be a concern. Previous launch vehicle studies conducted by ACO, that have included reliability analyses, have shown that if a launch vehicle has engine out capability in one or more of the stages, it's overall mission success to orbit improves greatly. Higher vehicle reliability to orbit could benefit NASA when launching high value, one-of-a-kind payloads and/or crew if the payload capability of the vehicle was still adequate when flying with engine out. It was decided to include in this study the effect of engine out on the payload capability of the $100 \mathrm{mt}$ vehicle. Engine out was evaluated for first stage only; second stage only; and for both stages. The results of these analyses are discussed below.

\section{A. Second Stage Engine Out (Vehicle 114.06.00)}

The first case analyzed has an engine out in the second stage. Once the first stage is separated, it is assumed only three of the four J-2X-285 engines in the second stage ignite. Since a quarter of the thrust becomes unavailable, the second stage propellant is adjusted to maximize the injected mass for the thrust that remains. This results in a propellant offload of $40 \%$ which in turn reduces the amount of payload the vehicle can now place into orbit compared to the nominal vehicle with no engine out. Part of this loss can be recovered in the current configuration by loading more propellant in the first stage. The nominal case with no engine out has a $9.5 \%$ first stage propellant offload. With engine out in the second stage the offload can be reduced to $1.3 \%$. The ideal delta $\mathrm{V}$ provided by the first stage increases over $8 \%$ to $48.5 \%$. This method results in a LEO payload of $89.0 \mathrm{mt}$ for a second stage engine out scenario compared to the $104.2 \mathrm{mt}$ capability of the nominal case (114.05.00).

The ascent profile is constrained to not exceed the dynamic pressure and acceleration of the design and construction of the original vehicle. This vehicle lifts off with a thrust to weight of 1.20. During the first stage burn it reaches a maximum dynamic pressure of 673 psf at 85.5 seconds into the flight. To avoid exceeding the same maximum acceleration as the original vehicle the first stage begins a continuous throttle at 153.73 seconds. The first stage continues to burn until 182.19 seconds into the flight where it reaches a maximum acceleration of $3.85 \mathrm{~g}$ 's and speed of mach 10.25. First stage burnout occurs at an altitude of 239,640 ft. Four seconds after the first stage separates the upper stage ignites with an initial thrust to weight of $0.841 \mathrm{~g}$ 's at an altitude of $251,042 \mathrm{ft}$ and a speed of mach 10.34. The shroud is jettisoned at a mach of 8.77 at 245.00 seconds into the flight at an altitude of 388,102 $\mathrm{ft}$. The second stage burns out with a thrust to weight of $2.61 \mathrm{~g}$ 's at 520.40 seconds into the flight while traveling at mach 12.06. At this point it inserts into an orbit of 30 by 130 nautical miles at an altitude of 87.2 nautical miles.

\section{B. First Stage Engine Out (Vehicle 114.07.00)}

In the second case of the engine out analysis, engine out is assumed to occur in the first stage immediately after liftoff. The loss of one sixth of the thrust at liftoff has an even greater impact on LEO payload than the loss of a quarter of the thrust at second stage ignition. In order to maintain a T/W at liftoff of $1.20,30.5 \%$ of the first stage propellant must be offloaded. A small portion of this loss is recovered by reducing the second stage propellant offload from $12.1 \%$ in the original $100 \mathrm{mt}$ vehicle to $11.4 \%$. The first stage ideal delta $\mathrm{V}$ drops from $40.3 \%$ to $34.6 \%$ of the total ideal delta V. Engine out in the first stage results in a significant payload loss of over $26 \mathrm{mt}$ to $77.9 \mathrm{mt}$.

As stated earlier, with an engine out at liftoff, the first stage propellant must be offloaded a total of $1.243 \mathrm{M}-\mathrm{lb}$ $(30.5 \%)$ from its original design to meet the minimum thrust to weight of 1.20 set forth in the ground rules. During the first stage burn this vehicle reaches a maximum dynamic pressure of $630 \mathrm{psf}$ at 82.86 seconds into the flight. The first stage continues to burn until 150.43 seconds into the flight where it reaches a maximum acceleration of $3.72 \mathrm{~g}$ 's and a mach of 5.68. First stage burnout occurs at an altitude of 174,093 ft. Four seconds after the first stage separates the upper stage ignites with an initial thrust to weight of $0.874 \mathrm{~g}$ 's at an altitude of $1185,049 \mathrm{ft}$ and a speed of mach 5.67. At 237.0 seconds into the flight the shroud is jettisoned at a speed of mach 7.10 and an altitude of $362,260 \mathrm{ft}$. The second stage burns out with a thrust to weight of $3.77 \mathrm{~g}$ 's at 522.58 seconds into the flight with speed of mach 12.04. At this point it inserts into an orbit of 30 by 130 nautical miles at an altitude of 87.2 nautical miles. 


\section{First and Second Stage Engine Out (Vehicle 114.08.00)}

The third case assumes engine out in both the first and second stage. Based on the previous two cases, the cumulative loss in LEO payload is expected to be over $41 \mathrm{mt}$. However, the large reduction in payload permits more propellant to be loaded in both stages. Once again, this action offsets some of the total payload loss. The ideal delta $\mathrm{V}$ split is similar to the nominal configuration with all engines burning. The first stage contributes $43.1 \%$ of the total ideal delta $\mathrm{V}$ and the second stage the remaining $56.9 \%$. The vehicle delivers $65.1 \mathrm{mt}$ of payload to LEO for the scenario of an engine out in both stages.

This vehicle lifts off with a thrust to weight of 1.20. During the first stage burn it reaches a maximum dynamic pressure of $661 \mathrm{psf}$ at 85.50 seconds into the flight. To avoid exceeding the same maximum acceleration as the original vehicle the first stage begins a continuous throttle at 153.77 seconds and an altitude of $166,331 \mathrm{ft}$. The first stage continues to burn until 169.80 seconds into the flight where it reaches a maximum acceleration of $3.85 \mathrm{~g}$ 's and a mach of 8.15. First stage burnout occurs at an altitude of 207,347 ft. Four seconds after the first stage separates the upper stage ignites with an initial thrust to weight of $0.885 \mathrm{~g}$ 's at an altitude of $218,234 \mathrm{ft}$ and a mach of 8.28. At 250.67 seconds into the flight the shroud is jettisoned at a speed of mach 8.33 and an altitude of $381,375 \mathrm{ft}$. At 508.56 seconds into flight the upper stage inserts into an orbit of 30 by 130 nautical miles at an altitude of 87.3 nautical miles. At burnout the upper stage is traveling at a speed of mach 12.05 and has a thrust to weight of 3.12 g's.

\section{Summary of Results of Launch Vehicle Family Using NHE}

The results of the launch vehicle concepts sized with the LOX-RP NHE are given below in Table 2. The thrust level of the NHE was sized at 1.08 M-lbf@SL/1.25M-lbf@Vac to meet the payload requirements set forth in the study.

Table 2 Results of 1.25 M-lbf@VAC NHE Vehicle Family

\begin{tabular}{|c|c|c|c|c|c|c|c|}
\hline \multirow[b]{2}{*}{$\begin{array}{c}\text { ACO } \\
\text { Vehicle \# }\end{array}$} & \multicolumn{2}{|c|}{ First Stage } & \multicolumn{2}{|c|}{ Second Stage } & \multicolumn{2}{|c|}{ LRB } & \multirow[b]{2}{*}{$\begin{array}{c}\text { LEO } \\
\text { Payload }\end{array}$} \\
\hline & $\begin{array}{l}\text { Diameter } \\
\text { Engines }\end{array}$ & $\begin{array}{c}\text { Dry Mass } \\
\text { Propellant Load } \\
\% \text { Offload } \\
\end{array}$ & $\begin{array}{l}\text { Diameter } \\
\text { Engines }\end{array}$ & $\begin{array}{c}\text { Dry Mass } \\
\text { Propellant Load } \\
\% \text { Offload } \\
\end{array}$ & $\begin{array}{l}\text { Diameter } \\
\text { Engines }\end{array}$ & $\begin{array}{c}\text { Dry Mass } \\
\text { Propellant Load }\end{array}$ & \\
\hline LV 114.04.00 & $\begin{array}{c}33 \mathrm{ft} \\
6-\mathrm{NHE}\end{array}$ & $\begin{array}{c}339 \mathrm{Klb} \\
4.07 \mathrm{Mlb} \\
0 \%\end{array}$ & $\begin{array}{c}33 \mathrm{ft} \\
4-J-2 X-285\end{array}$ & $\begin{array}{c}112 \mathrm{Klb} \\
1.08 \mathrm{Mlb} \\
0 \%\end{array}$ & $\begin{array}{c}14.2 \mathrm{ft} \\
1-\mathrm{NHE}\end{array}$ & $\begin{array}{c}92 \mathrm{Klb} \\
501 \mathrm{Klb}\end{array}$ & $143.7 \mathrm{mt}$ \\
\hline LV 114.05.00 & $\begin{array}{c}33 \mathrm{ft} \\
6-\mathrm{NHE}\end{array}$ & $\begin{array}{c}337 \mathrm{Klb} \\
3.69 \mathrm{Mlb} \\
9.5 \% \\
\end{array}$ & $\begin{array}{c}33 \mathrm{ft} \\
4-J-2 X-285\end{array}$ & $\begin{array}{c}112 \mathrm{Klb} \\
955 \mathrm{Klb} \\
12.1 \% \\
\end{array}$ & $\mathrm{n} / \mathrm{a}$ & $\mathrm{n} / \mathrm{a}$ & $104.2 \mathrm{mt}$ \\
\hline LV 114.06.00 & $\begin{array}{c}33 \mathrm{ft} \\
6-\mathrm{NHE}\end{array}$ & $\begin{array}{c}337 \mathrm{Klb} \\
4.02 \mathrm{Mlb} \\
1.3 \%\end{array}$ & $\begin{array}{c}33 \mathrm{ft} \\
4-\mathrm{J}-2 \mathrm{X}-285 \\
1-\text { Eng Out }\end{array}$ & $\begin{array}{c}112 \mathrm{Klb} \\
655 \mathrm{Klb} \\
40.0 \%\end{array}$ & $\mathrm{n} / \mathrm{a}$ & $\mathrm{n} / \mathrm{a}$ & $89.0 \mathrm{mt}$ \\
\hline LV 114.07.00 & $\begin{array}{c}33 \mathrm{ft} \\
6-\mathrm{NHE} \\
1-\text { Eng Out }\end{array}$ & $\begin{array}{c}337 \mathrm{Klb} \\
2.83 \mathrm{Mlb} \\
30.5 \%\end{array}$ & $\begin{array}{c}33 \mathrm{ft} \\
4-\mathrm{J}-2 \mathrm{X}-285\end{array}$ & $\begin{array}{c}112 \mathrm{Klb} \\
963 \mathrm{Klb} \\
11.4 \%\end{array}$ & $\mathrm{n} / \mathrm{a}$ & $\mathrm{n} / \mathrm{a}$ & $77.9 \mathrm{mt}$ \\
\hline LV 114.08 .00 & $\begin{array}{c}33 \mathrm{ft} \\
6-\mathrm{NHE} \\
1-\text { Eng Out }\end{array}$ & $\begin{array}{c}337 \mathrm{Klb} \\
3.17 \mathrm{Mlb} \\
22.2 \%\end{array}$ & $\begin{array}{c}33 \mathrm{ft} \\
4-\mathrm{J}-2 \mathrm{X}-285 \\
1-\text { Eng Out }\end{array}$ & $\begin{array}{c}112 \mathrm{Klb} \\
656 \mathrm{Klb} \\
39.6 \%\end{array}$ & $\mathrm{n} / \mathrm{a}$ & $\mathrm{n} / \mathrm{a}$ & $65.1 \mathrm{mt}$ \\
\hline LV 114.09.00 & $\begin{array}{c}14.2 \mathrm{ft} \\
1-\mathrm{NHE}\end{array}$ & $\begin{array}{c}69.2 \mathrm{Klb} \\
719 \mathrm{Klb} \\
\mathrm{n} / \mathrm{a} \\
\end{array}$ & $\begin{array}{c}12.5 \mathrm{ft} \\
2-\mathrm{RL}-10 \mathrm{~A} 4-3\end{array}$ & $\begin{array}{c}11 \mathrm{Klb} \\
59.3 \mathrm{Klb} \\
\mathrm{n} / \mathrm{a} \\
\end{array}$ & $\mathrm{n} / \mathrm{a}$ & $\mathrm{n} / \mathrm{a}$ & $11.5 \mathrm{mt}$ \\
\hline LV 114.01.02 & $\begin{array}{c}14.2 \mathrm{ft} \\
1-\mathrm{NHE}\end{array}$ & $\begin{array}{c}65.0 \mathrm{Klb} \\
501 \mathrm{Klb} \\
\mathrm{n} / \mathrm{a}\end{array}$ & $\begin{array}{c}16.7 \mathrm{ft} \\
1-\mathrm{J}-2 \mathrm{X}-285\end{array}$ & $\begin{array}{c}30 \mathrm{Klb} \\
256 \mathrm{Klb} \\
\mathrm{n} / \mathrm{a}\end{array}$ & $\mathrm{n} / \mathrm{a}$ & $\mathrm{n} / \mathrm{a}$ & $12.9 \mathrm{mt}$ \\
\hline
\end{tabular}

The results show that a family of vehicles with a broad range of payload capabilities can be derived from a single initial launch vehicle development using the same stage elements and engines. The initial vehicle concept 114.04.00 sized the first stage, the second stage, and the LRB. Vehicle concepts 114.05.00, 114.06.00, 114.07.00, 114.08.00 utilized the same first stage and second stage of vehicle 114.04.00 but did not include the strap-on LRBs. The small difference in dry mass of the first stage of 114.04 .00 and the other vehicles listed (339 k-lbm vs. $337 \mathrm{k}-1 \mathrm{bm}$ ) was for 
the attach structure carried by the first stage for the LRBs. Heavy lift capabilities of $140 \mathrm{mt}$ and $100 \mathrm{mt}$ are achievable with this approach for a NHE thrust level defined in this study. For high value payloads or crewed missions where a greater degree of reliability in the launch vehicle is desired, engine out can be incorporated into the mission planning and lift capabilities of $65 \mathrm{mt}$ to nearly $90 \mathrm{mt}$ can still be achieved with this vehicle approach. The LRB can also be modified for use as a first stage in conjunction with a LOX-LH2 second stage for smaller payloads in the $12 \mathrm{mt}$ range.

\section{Conclusion}

A launch vehicle family utilizing a new hydrocarbon engine with 1.08 M-lbf@SL/1.25M-lbf@Vac thrust characteristics can provide the lift capability to meet the future exploration missions of NASA. This new engine could also potentially have broader application for use in future expendable and reusable launch vehicles for the Air Force/Department of Defense as well as enhancing the commercial launch industry making it a truly "National" rocket engine.

\section{Appendix}

The Ground Rules and Assumptions used in the launch vehicle performance and sizing analyses for this study are listed below.

\section{General GR\&A}

\section{Configuration}

- $\quad$ VAB Launch Vehicle Stack Integrated Height Constraint $=390 \mathrm{ft}$.

- $\quad$ Maximum Stage Length = $234 \mathrm{ft}$. (VAB diaphragm limit)

- All Vehicle Stages: Diameter Constraint = up to $33 \mathrm{ft}$. Diameters reported as outside diameters.

- Two stage liquid propulsion with possible liquid rocket booster strap-ons

\section{Payload Definitions}

- Payload is defined as the total injected mass at destination Low Earth Orbit (LEO) minus the burnout mass of the final stage.

\section{Payload Margin}

- Any payload margin is included in the gross mass delivered to the final destination.

\section{Trajectory / Ascent Flight Profile}

General Trajectory GR\&A

- $\quad$ Baseline Trajectory Model will be generated using POST 3D, a 3-DOF point mass trajectory simulation.

- Max acceleration not to exceed 5.0 g's.

- Max dynamic pressure not to exceed 800 psf

- $\quad$ Launch from Pad 39A: gdlat $=28.608422 \mathrm{deg}$, long $=279.395910 \mathrm{deg}$, gdalt $=0 \mathrm{ft}$

- Minimum Thrust/Weight at liftoff of 1.20 .

- $\quad$ Grace GM02C gravity model

- Gram2007-Mean_Annual_Atmosphere-October2008 (EV44)

- Gram2007-Mean_Annual_Winds-October2008 (EV44)

- Start simulation at lift-off

- Begin pitch-over at tower clearance (450 ft altitude).

- $\quad$ Pitch over ends and gravity turn begins when $\mathrm{Q}=150$ psf.

- Alpha and sideslip angles are set to 0 during gravity turn.

- $\quad$ Gravity turn ends when $\mathrm{Q}=100$ psf.

- Optimized pitch profile after gravity turn

- Avoid instantaneous changes in vehicle attitude

- Serial burn staging events occur after core engine shutdown period/jettison, $+4.0 \mathrm{sec}$ coast.

\section{Orbital Injection into LEO}

- $\quad$ Perigee and apogee are relative to a spherical earth whose radius equals earth's mean equatorial radius.

- $\quad$ MECO altitude is optimized for elliptical orbits, but must be $\geq 75 \mathrm{nmi}$ (driven by heating rate constraint). 
- Gross payload capability will be analyzed for $30 \mathrm{nmi}$ x $130 \mathrm{nmi} @ 29^{\circ}$, orbital circularization assumed to be provided by the payload.

\section{Payload Fairings}

- Fairing is Bi-Conic shaped.

- Fairing material assumed to be Al-Li 2195.

- Fairing structural weight is determined by structural analysis.

- Fairing jettison weight includes: structures, TPS and acoustic/thermal blankets.

- Fairing jettisoned after 1st stage separation and when 3-sigma Free Molecular Heating Rate $<0.1 \mathrm{BTU} / \mathrm{ft}^{2}$ sec.

- $\quad 3-\sigma F M H R=\left(1 / 2 \rho \mathrm{V}^{3}\right)(\mathrm{K}$-factor $)=($ dynp $)($ vela $)(\mathrm{K}$-factor $)($ conv $)$

- dynp = dynamic pressure; vela $=$ atmospheric relative velocity

- $\mathrm{K}$-factor $=2.0$ (atmospheric density doubled to account for dispersions)

- $\operatorname{conv}=0.00128593 \mathrm{BTU} / \mathrm{ft}-\mathrm{lb}$ units conversion factor

\section{Payload Volume}

- $\quad 33.0 \mathrm{ft}(10 \mathrm{~m})$ Fairing:

○ $140 \mathrm{mt}$ class $-82.0 \mathrm{ft}(25.0 \mathrm{~m})$ length $\mathrm{x} 30.0 \mathrm{ft}(9.1 \mathrm{~m})$ diameter dynamic envelope.

○ $\quad 100 \mathrm{mt}$ class $-60.0 \mathrm{ft}(18.3 \mathrm{~m})$ length $\times 30.0 \mathrm{ft}(9.1 \mathrm{~m})$ diameter dynamic envelope.

\section{Aerodynamics}

- 3-DOF aero and base force generated by EV33 for HLLV 2.5 Stage February 2009 generated for Ares V.

\section{Weights \& Sizing (INTROS)}

\section{General W\&S GR\&A}

- Dry mass margins:

- Based on MGA schedule consistent with SAWE recommended practices.

- Note: Propellant tanks 15\%, all other structures $18 \%$.

- $\quad$ Composite structures $=25 \%$

- Propellant density:

- LOX: $71.04 \mathrm{lbm} / \mathrm{ft}^{3}$

- LH2: $4.404 \mathrm{lbm} / \mathrm{ft}^{3}$

- RP: $50.50 \mathrm{lbm} / \mathrm{ft}^{3}$

- Unusable Tank Volume of 2\% for all stages (Ullage /Manufacturing Tolerance/Loading Accuracy/Internal Equipment \& Structures/Cryo Tank Shrinkage).

- Miscellaneous Secondary Structures calculated as 5\% of LVA Primary Structures.

- Vehicle sizing is considered closed when the payload capability is between the target payload and the target payload plus $0.1 \%$.

\section{Propellant Allocation:}

- FPR:

- $\quad \mathrm{FPR}$ is $1 \%$ of the total ideal $\mathrm{dV}$ for the mission.

- Final stage carries the entire FPR.

- Any excess FPR is not calculated as payload.

- Fuel bias:

- $0.0013 *$ mixture ratio / $5.29 *$ usable propellant (based on INTROS MER)

- Residuals:

- $\quad 0.0631 *$ (usable propellant)^ 0.8469 (based on INTROS MER)

- Start propellant: 
- $\quad 1^{\text {st }}$ stage calculated based on engine startup transients.

- Air Start Stages: zero start propellant allocated

\section{$\underline{\text { Structures (LVA) }}$}

\section{General Structural GR\&A}

- $\quad$ Launch vehicle safety factors for new stages $=1.4$ ultimate strength (consistent with NASA-STD-5001)

- Closing criteria for INTROS - In LVA add:

- Design liftoff acceleration = as flown in Trajectory (POST) plus $0.1 \mathrm{~g}$.

- Design max acceleration $=$ as flown in Trajectory $($ POST) plus $0.1 \mathrm{~g}$.

- Design max dynamic pressure = as flown in Trajectory (POST) plus $10 \mathrm{psf}$.

- $\quad$ Payload = as flown in Trajectory (POST) plus 5,000 lbs

- For propellant tanks, use 50 psia MEOP (50 psid). Head pressure is in addition to ullage pressure.

- Pressure relief of flight loads on Core and Upper Stages.

- For tanks with pressure relief of flight loads use $30 \mathrm{psia}(30 \mathrm{psi}-14.7 \mathrm{psi}=15.3 \mathrm{psid})$. No safety factor on pressure relief load.

- 3 sigma dispersion estimation on angle of attack.

- Structural buckling knockdown factor of 0.65 (SBKF).

- No proof analysis on tanks.

- Used combined worst-case loads analysis in LVA (i.e. all worst case loads happen simultaneously) with a 1.3 load uncertainty factor applied. (This matches very closely individually run load cases with a dispersed max q and a 1.5 load uncertainty factor).

\section{Material Properties Assumptions:}

- $\quad 1$ st stage - Al-Li 2195 all structures

- Upper Stages - Al-Li 2195 all structures

- Shroud - IM7 composite

- Al-Li 2195: Properties consistent with EV30 assumptions, but no limit on plate thickness.

- Composites: IM7/8552 quasi-isotropic if utilized

- 1 st stage uses Room Temperature material properties

- Upper Stages use Cryogenic material properties (if available) 